\title{
Avaliação da toxicidade de estirpes de Bacillus thuringiensis para Aedes aegypti Linneus, (Díptera: Culicidae)
}

\author{
Marcio Akio Ootani ${ }^{*}$, Antonio Carlos Costa Ramos ${ }^{1}$, Emiliano Bradão de Azevedo ${ }^{1}$, \\ Bruno de Oliveira Garcia ${ }^{1}$, Suetonio Fernandes dos $\operatorname{Santos}^{1}$ e Raimundo Wagner de Sousa \\ Aguiar $^{1}$
}

${ }^{l}$ Departamento de Agronomia; Universidade Federal do Tocantins; 77402-970; Gurupi - TO - Brasil.

\begin{abstract}
ABSTRAT
This work was aimed at to select and to identify strain of Bacillus thuringiensis (Bt) obtained of samples of soil in the state of Tocantins that presented toxicity for the mosquito Aedes aegypti. It was obtained isolated of Bt of the samples of obtained soils and with larger number of colonies in soils with high clay tenor and organic matter. The poisonous activity among the isolated ones obtained it varied by 14.7 to $98 \%$ of mortality to larvas of $2^{\circ}$ stadium of A. aegypti, with prominence for the isolated TO-392. They were accomplished analyzes for SDS-PAGE where there was the presence of a peptides of approximately $80 \mathrm{kDa}$, wasn't visualized us too much isolated, the ancestry A-392 had $98 \%$ of mortality about larvas of $A$. aegypt was tested $i$, in the period of 48 hours, using a concentration of 1 and $2 \% \square$ of the bacterial .broth. It is verified that B. Thuringiensis isolated of the state of Tocantins presents promising results for they can be used in the production of a bioinseticide against the larvas of this mosquito.
\end{abstract}

Key words: Dengue fever; bio-insecticide, control biological

\section{INTRODUÇÃO}

Aedes aegypti Linneus, 1762 (Díptera: Culicidae) é um inseto de ocorrência nas regiões tropicais e subtropicais. No Brasil, está restrito às vilas e cidades que apresentam características favoráveis ao desenvolvimento do mosquito e, raramente é encontrado em ambientes onde a densidade populacional é baixa. Este mosquito é o único vetor do vírus da dengue e da febre amarela urbana, sendo considerado um dos vetores mais importantes na veiculação desse vírus em humanos (Brasil, 2009). O reaparecimento dessa doença se tornou um serio problema de saúde publica no Brasil.

Por ser uma técnica efetiva, de baixo custo e de fácil manejo, o controle químico tem sido a forma mais usada no controle de $A$. aegypti em todos estados brasileiros. No entanto, devido à ineficiência dos produtos químicos em controlar esse inseto, o uso sistematizado tem ocasionado o aparecimento de populações resistentes de $A$. aegypti a esses produtos (Guzman e Kouri, 2002; Lima et al., 2003; Carvalho et al., 2004; Poupardina et al., 2008; Chang et al., 2009) além do aumento do risco ambiental e o custo de controle, por ser realizado varias aplicações para garantir um resultado satisfatório.

Dessa forma, há necessidade do desenvolvimento de novas alternativa menos danosa. Os bioinseticidas aparecem como resposta à crescente preocupação com o meio ambiente, se mostrando eficiente no controle de insetos vetores, mas com poucos danos ao ambiente (Marcoris et al, 2003) A descoberta da bactéria de solo Gram positiva Bacillus thuringienses (Bt), produtora de toxina que possuem propriedade altamente tóxica, principalmente para as larvas de dípteros da família Culicidae, possuindo vantagens como não poluir o meio ambiente, não ser tóxico aos animais, possibilitou o desenvolvimento de novos bioinseticidas que se tornou uma alternativa segura. Principalmente devido à grande produção de proteínas (denominadas de proteínas Cry) com atividade entomopatogênica durante a fase de esporulação, formando inclusões cristalinas (Shnepf et al., 1998; Araújo et al., 2007; Tikar el al., 2009).

Formulações de bioinseticidas à base de $B$. thuringiensis vêm sendo comercializadas em vários países do mundo para o controle de vetores

Author for correspondence: ootani667@uft.edu.br 
de doenças humanas (Petry et al., 2004; Vilarinhos e Monnerat, 2004; Espíndola et al., 2008), representando atualmente de 80 a $90 \%$ do mercado de agentes biológicos para o controle de mosquito em todo o mundo. $\mathrm{O} B$. thuringiensis possui diversas proteínas Cry ativas contra díptero, que são codificadas por diferentes genes cry e estão distribuídos em várias classes. O número de cópias de cada gene cry presente em uma determinada estirpe é um fator fundamental na determinação da toxicidade de uma estirpe de B. thuringiensis, assim como, na produção relativa de cada tipo de proteína Cry e, conseqüentemente, no espectro de atividade entomocida (Vilarinhos et al., 1998; Petry et al., 2004; Espíndola et al., 2008).

A presente pesquisa tem como objetivo selecionar estirpes de $B$. thuringiensis com atividade tóxica para Aedes Aegypti Linneus (Díptera: Culicidae) amostra de solo do estado do Tocantins.

\section{MATERIAL E MÉTODOS}

Para realização deste estudo os trabalhos foram conduzidos nos laboratórios de manejo integrado de pragas (MIP) do Campus Universitário de Gurupi - Universidade Federal do Tocantins. Para a realização desse projeto foram efetuadas as seguintes etapas e procedimentos metodológicos.

\section{Criação massal de $A$. aegypti}

Foram utilizadas posturas de A. aegypti obtidas junto à criação desse inseto presente no laboratório de Manejo Integrado de Pragas instalado no Campus Universitário de Gurupi/TO. Para a obtenção das diferentes fases de desenvolvimento do inseto, a serem utilizadas nos bioensaios, as posturas coletadas da criação massal de $A$. aegypti foram colocadas em bandejas com água e acondicionadas em uma câmara incubadora tipo Biological Oxigen Demand (B.O.D), regulada para $28 \pm 0,5{ }^{\circ} \mathrm{C}, 70 \pm 10 \%$ de UR e 12 horas de fotofase. A partir da primeira muda, as larvas foram utilizadas nos bioensaios seletivos, com diferentes isolados de $B t$ obtidos de solos do estado do Tocantins.

\section{Isolamento de $B$. thuringiensis a partir de amostras de solos}

Para o isolamento, foram utilizadas amostras de solos coletadas de diferentes localidades do estado do Tocantins. Nesse procedimento, os métodos utilizados para obter os isolados foram os mesmos desenvolvidos por Monnerat et al. (2001), onde cada amostra de $1 \mathrm{~g}$ de solo será homogeneizado em $10 \mathrm{~mL}$ de solução salina $(0,006 \mathrm{mM}$ $\mathrm{FeSO}_{4} .7 \mathrm{H}_{2} \mathrm{O} ; 0,01 \mathrm{mM} \quad \mathrm{CaCO}_{3} 7 \mathrm{H}_{2} \mathrm{O} ; 0,08 \mathrm{mM}$ $\mathrm{MgSO}_{4} \cdot \mathrm{H}_{2} \mathrm{O} ; 0,07 \mathrm{mM} \mathrm{MnSO}{ }_{4} \cdot 7 \mathrm{H}_{2} \mathrm{O} ; 0,006 \mathrm{mM}$ $\mathrm{ZnSO}_{4} \cdot 7 \mathrm{H}_{2} \mathrm{O} ; \mathrm{pH} 7,0$ ) e foi colocada para crescer em um período de $24 \mathrm{~h}$. Uma alíquota de $1 \mathrm{~mL}$ será transferida para tubo de microcentrífuga tipo "eppendorf" e, após choque térmico $\left(80^{\circ} \mathrm{C}\right.$ por 12 min) para eliminar as células vegetativas, serão diluídas 10 vezes em solução salina. Uma alíquota de $100 \mu \mathrm{l}$ da última diluição será distribuída em uma placa de Petri contendo agar nutritivo $(0,5 \%$ de extrato de levedura; $0,1 \%$ de triptona; $0,17 \mathrm{M}$ $\mathrm{NaCl}$ e $0,15 \%$ de agar bacteriológico. O material foi mantido em B.O.D., $30 \pm 0,5^{\circ} \mathrm{C}$ durante $48 \mathrm{~h}$. As colônias foram selecionadas em meio seletivo para B. thuringiensis, contendo ampicilina $\mathrm{G}$ a 100 $\mathrm{mg} / \mathrm{L}$ e as mesmas foram avaliadas quanto à morfologia (forma, bordo, elevação, estrutura, tamanho e coloração), utilizando-se um contador de colônias (Jung et al., 1998). Os isolados inoculados foram mantidos $24 \mathrm{~h}$ a $30 \pm 0,5{ }^{\circ} \mathrm{C}$ e $180 \mathrm{rpm}$ em um agitador orbital. Após este período, cada amostra foi individualmente analisada quanto ao crescimento do microorganismo. Em seguida, foram preparadas lâminas e observadas em microscopia de contraste de fase $(1000 \mathrm{x})$, para a verificação da presença de corpos de inclusões parasporais (cristais) que permitiram a diferenciação entre $B$. thuringiensis (com cristais) e B. cereus (sem cristais). Foi calculado o índice de $\mathrm{Bt}(B t i)$, que corresponde ao número de isolados de $B t$ obtidos em relação ao número de colônias examinadas em cada amostra.

\section{Análise SDS-PAGE}

Esse procedimento foi realizado com estirpes selecionadas nos bioensaios seletivos, tóxicos. A análise das proteínas presentes nas estirpes foi determinada através de eletroforese de proteínas em gel de poliacrilamida (SDS-PAGE 10\%) que permitiu conhecer o perfil e a massa molecular das toxinas produzidas pelas estirpes. As proteínas produzidas por B. thuringiensis foram extraídas de acordo com Lecadet et al. (1991). As estirpes selecionadas foram crescidas em meio NYSM (Yousten, 1984) $30{ }^{\circ} \mathrm{C}$ por $48 \mathrm{~h}$ a $180 \mathrm{rpm}$ em um agitador orbital.Em seguida, $1 \mathrm{~mL}$ do cultivo de cada estirpe foi colocado em "eppendorf", previamente autoclavado, e centrifugado por $5 \mathrm{~min}$ a $12.800 \mathrm{~g}$. O sobrenadante foi descartado, o sedimento foi lavado com $1 \mathrm{ml}$ de $\mathrm{NaCl} 0,15 \mathrm{M}$ e centrifugado novamente a $12.800 \mathrm{~g}$ por $5 \mathrm{~min}$. $\mathrm{O}$ sobrenadante foi descartado e o sedimento 
ressuspendido em $1 \mathrm{ml}$ de PMSF $1 \mathrm{mM}$. Após nova centrifugação $(12.800 \mathrm{~g}$ por $5 \mathrm{~min})$, o sobrenadante foi descartado e o sedimento ressuspendido em $250 \mu \mathrm{l}$ de PMSF $1 \mathrm{mM}$ para estoque em freezer ($20{ }^{\circ} \mathrm{C}$ ). As amostras foram ressuspendidas em tampão de proteína $5 \mathrm{X}(1,5 \mathrm{M}$ Tris-HCl, $\mathrm{pH}$ 6,8,

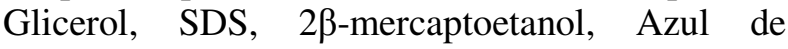
Bromofenol) fervidas a $100^{\circ} \mathrm{C}$ por 5 min e aplicadas em gel de poliacrilamida SDS-PAGE numa concentração de $10 \%$. O gel foi corado em solução "Comassie Blue corante" $(40 \%$ de metanol e $25 \%$ de Comassie blue 250-R) por $12 \mathrm{~h}$ e descorado em solução descorante $(40 \%$ de metanol e $10 \%$ de ácido acético) até visualização das bandas de proteínas que correspondem às toxinas presentes. Para comparação dos resultados obtidos das estirpes selecionadas, foram utilizadas como padrões estirpes de $B$. thuringiensis israelensis e $B$. thuringiensis aizawai.

\section{Bioensaios}

Os bioensaios foram feitos seguindo os padrões previamentes propostos com os isolados de $B$. thuringiensis contra larvas de $2^{\circ}$ ínstar de $A$. aegypti. Para a realização do bioensaios seletivo, foi colocado 1 e $2 \%$ de caldo bacteriano crescido em meio NYSM (Yousten, 1984) por $48 \mathrm{~h}$ a $28^{\circ} \mathrm{C}$ sob agitação de $200 \mathrm{rpm}$, foi colocado em $100 \mathrm{ml}$ de água em 4 copos descartáveis, contendo grupos de 25 larvas de $2^{\circ}$ ínstar de A. aegypti. Foram feitas quatro repetições e com a testemunha sem a cultura bacteriana. Após 48h, realizou-se a leitura do numero de sobreviventes. Determinando as estirpes tóxicas para larvas de $A$. aegypti, após 48 $\mathrm{h}$ de contato de acordo com a metodologia desenvolvidas por Monnerat et al. (2001).

\section{RESULTADOS E DISCUSSÃO}

Foram obtidos um total de 101 colônias a partir de cinco amostras de solos coletadas de diferentes localidades do Estado do Tocantins. O número de isolados obtidos em relação à amostra de solos foi diferenciado (Tabela 1). Entre amostras de solos A-392, A-3118 e A-3452 obtiveram os maiores números de colônias, enquanto A-100 e A-100 e A-5451, obtiveram o menor número de colônias de $B t$ (tabela 1). A variação do número de colônias bacterianas obtidas entre as amostras de solo pode está relacionado com tipos de solos, de acordo com estudos relacionados à ocorrência do $B t$ é relatada em todos os ambientes terrestres, principalmente devido à sua capacidade de sobrevivência em condições adversas e fácil transporte pelo vento, chuva e animais, dificulta comparações entre tipos de solos, especialmente entre regiões geograficamente diferentes, com condições climáticas e solos distintos (Cox et al., 2007).

Tabela 1. Características das amostras dos solos coletados e os isolados de Bacillus thuringiensis ativos para Aedes aegypti.

\begin{tabular}{cccc}
\hline Amostra de Solo & Tipo de solo & $\mathbf{N}^{\mathbf{0}}$ de Amostra & Medias (NC) \\
\hline A-3188 & argiloso & 01 & 18 \\
A-100 & argiloso & 01 & 12 \\
A-5451 & (+/-) argiloso & 01 & 13 \\
A-392 & argiloso & 01 & 31 \\
A-3452 & argiloso & 01 & 27 \\
\hline
\end{tabular}

NC-Número de colônias de $B t$

Embora o $B t$ seja uma bactéria esporulante, os esporos permanecem em latência no solo entre $3 \mathrm{e}$ 16 meses (Goldberg e Margalit 1977; Couch, 2000; Becker, 2002). No entanto, o crescimento e a germinação dos esporos podem ser prejudicados em função das características do solo. Dessa forma, solos arenosos, devido a pouca quantidade de nutrientes e água sempre apresentam menor quantidade de isolados de $B t$ (Glare e O'callaghan, 2000). Mas, em ambientes favoráveis, como, por exemplo, em insetos alvo, e solos argilosos a bactéria ocorre naturalmente, pode ocorrer relação simbiótica com plantas como bactéria endofítico (Uribe et al., 2003; Monnerat et al., 2009).

$\mathrm{Na}$ identificação das estirpes de $B t$ selecionadas em meio seletivo NYSM (Yousten, 1984) adicionado de $100 \mathrm{mg} / \mathrm{L}$ de penicilina, após um período de 48 horas foram observados a presença de cristal produzido pelas estirpes selecionadas em microscopia de contraste de fase, da mesma forma foi observada em algumas estirpes havia somente a presença de esporos e células vegetativa sem 
cristal, sendo caracterizada com Bacillus cereus (Tabela 1). Monerrat et al. (2001) observou que um dos processos de diferenças entre $B$. thuringiensis e $B$. cereus esta relacionado com a produção de cristal por $B$. thuringiensis e a não presença de cristal em $B$. cereus sendo confirmado em microscopia de luz em contraste de fase.

Quanto à morfologia das colônias de $B t$ obtidas, verificaram-se poucas variações, sendo que a maioria apresenta forma circular e bordos ondulados. Na sua totalidade, as colônias apresentaram-se sem pigmentação, opacas e com estrutura densa. Esses dados estão de acordo com dados obtidos por Sosa-Gomes et al. (1998), os quais descreveram as colônias típicas dos bacilos com ausência de pigmentação, bordos ondulados e opacos. Por outro lado, cabe ressaltar que Habib e Andrade (1998) mostraram que critérios morfológicos não podem ser empregados na diferenciação e identificação dos bacilos, indicando assim a necessidade de outras avaliações para inferir no processo de diferenciação e identificação das espécies e subespécies de Bacillus.

Com relação ao perfil protéico produzido pelas estirpes selecionadas em análise da eletroforese em gel de poliacrilamida (SDS-PAGE) dos cristais purificados das estirpes com atividade tóxica para A. aegypti mostrou dois polipeptídios principais de aproximadamente de $75 \mathrm{kDa}$ (Figura 1) correspondente ao tamanho do polipeptídios produzidos pelas estirpes de $B$. thuringiensis subespécie israelense que produz alta toxicidade para A. aegypti.

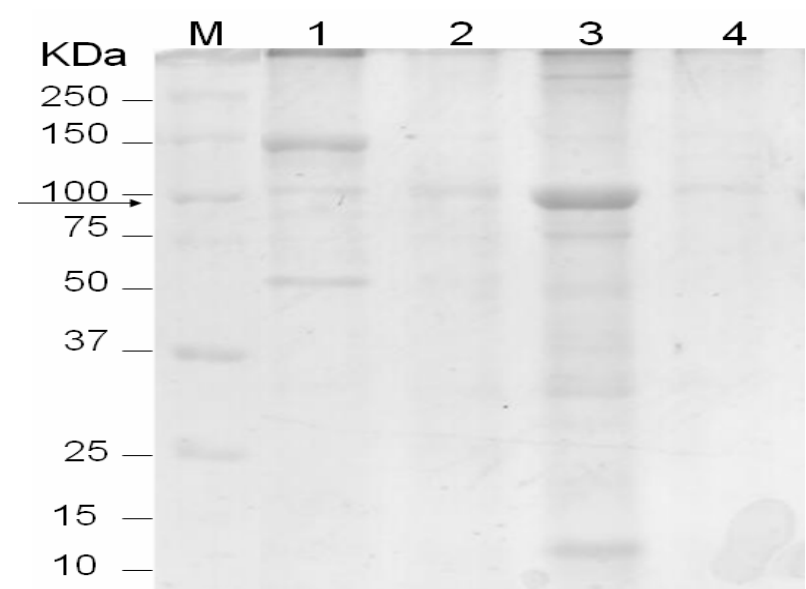

Figura 1- Análise do perfil protéico das estirpes isolados de solo do estado do Tocantins. A e B SDSPAGE a $12 \%$ das proteínas Cry produzida pelas diferentes estirpes de $B t$ selecionadas com toxicidades para larvas de A. aegypti sendo M- marcado molecular Kaleidoscope Bio-Rad,1- estirpe 3453, 2- estirpe A3188, 3 A-392, e 4- A-5451.

Segundo trabalhos desenvolvidos por Espíndola et al. (2008) relataram que as toxinas descritas como eficazes para dípteros possuem peso molecular de $75 \mathrm{kDa}$ e $81 \mathrm{kDa}$, o que pode explicar a toxicidade para larvas de A. aegypti. Dessa maneira, uma possível explicação para a elevada toxicidade de A-392 para A. aegypti pode esta relacionado com presença das toxinas, os quais conferem potencial tóxico significativamente para larvas de $A$. aegypti (Espíndola et al., 2008), ou com à interação entre as toxinas produzida por este isolado.

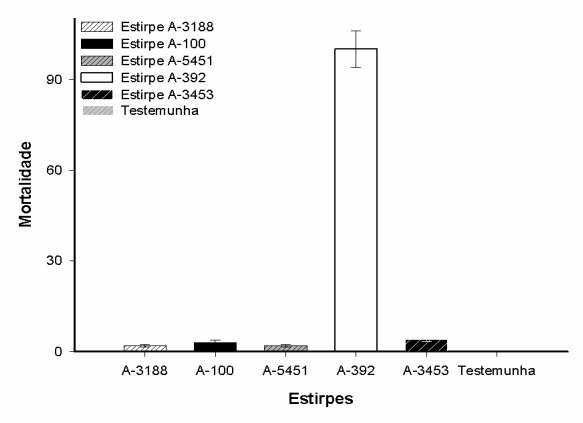

Figura 2- Análise de toxidade das estirpes selecionadas para larvas de Aedes aegypti selecionadas de amostras de solos. Após o período de 48 horas de exposição às bactérias isoladas.

Nos testes de patogenicidade, os isolados testados somente um (1) foi capaz de causar alta mortalidade das larvas de A. aegypti após o período de 48 horas (Figura 3). Neste caso destacou-se o isolado A-392 obtido do laboratório de solos do Campus Universitário de Gurupi/UFT. Para os demais isolados, a mortalidade das larvas de Aedes foi inferior a $10 \%$ (Figura 1). De acordo com Vilarinhos et al. (1998) a eficiência das formulações varia de $96 \%$ a $100 \%$ até um período de $72 \mathrm{~h}$ após a aplicação dos produtos. Com esta alta eficiência, apesar da Bti atuar somente sobre larvas, ele restringe o nível populacional do $A$. aegypti de tal modo que o inseto seja incapaz de causar epidemia. De um modo geral, em 2002, aproximadamente 360 toneladas de Bti foram usadas no combate de vetores no Brasil (Brasil, 2009), consumindo US $\$ 2,2$ milhões. 


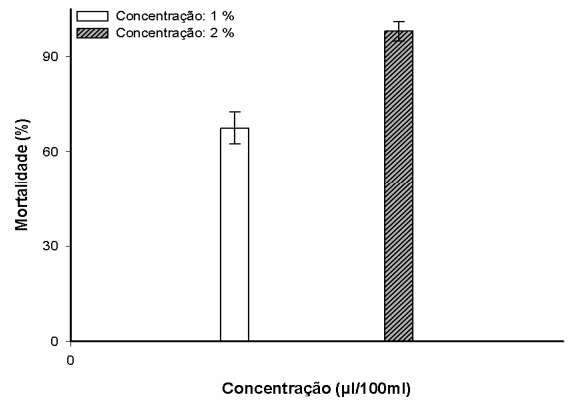

Figura 3- Análise de toxidade da estirpe A-392 para larvas de $1^{\circ}$ estádio de Aedes aegypti em duas concentrações após o período de 48 horas de exposição à toxina da bactéria.

A patogenicidade de isolados de $B$. thuringiensis está relacionada com número de cópias dos genes cry, assim como, a diferença entre a composição gênica, associado a esse fato, o espectro de atividade entomocida pode ser ampliada em função desta característica (Petry et al., 2004; Prabakaran et al., 2008). Por ser um microorganismo promissor, atualmente há uma enorme procura por novos isolados de $B$. thuringiensis com elevado potencial tóxico para larvas de A. aegypti.

A dificuldade de obtenção de novos isolados de $B t$ eficazes contra larvas de $A$. aegypti, constatada nesse trabalho, também foi relatada por Jung et al. (1998). Os autores testaram 352 isolados do Brasil e somente um causou mortalidade entre 70 a $80 \%$, enquanto 149 deles mostraram resultados entre $0 \mathrm{e}$ $10 \%$. Hofte e Whiteley (1989), testou 52 isolados e somente dois proporcionaram $100 \%$ de mortalidade. Dessa maneira, verificou a toxicidade de diferentes isolados de $B$. thuringiensis para larvas de $A$. aegypti, com alta variabilidade genética nessas populações que resulta em grupos que não possui receptores para uma determinada toxina Cry, tornando inacessível a ligação das toxinas de B.thuringiensis aos receptores especifico, tornando insetos resistentes a uma determinada combinação de toxinas de $B$. thuringiensis ou uma proteína Cry.

Diversos insetos da ordem díptera possuem suscetibilidade às proteínas Cry de $B t$, tais como: Culex quiquefasciatus e aedes aegytpi (Díptera: Culicidade). Independente da fonte de obtenção do microrganismo, seja ela isolada de fontes naturais como solo ou inseto, ou obtida por manipulação genética, todos os novos isolados obtidos deverão seguir a etapa de otimização antes de poder ser utilizados na formulação do bioinseticidas. Atualmente são empregados como método de controle de insetos vetores em diversos países, principalmente em países da África Ocidental, como componentes do Programa de Controle de Oncocercose e atualmente passou a ser usada como uma alternativa para inseticidas químicos sintéticos em muitos programas de controle de mosquitos (Who, 1999).

A busca de novas alternativas para o controle de $A$. aegypti, principalmente na redução de insetos resistentes a inseticidas convencionais, a utilização de $B t i$ tem sido alvo de inúmeras pesquisas, com uso de Bti no controle de A. aegypti em diversos países como Peru, Equador e na região Amazônica do Peru (Kroeger et al., 1995). Dez semanas após a aplicação, foi observada uma redução média de $60 \%$ na população de adultos. Em 1981, a campanha de erradicação de A. Aegypti, realizada em Cuba, combinou a redução de criadouros do mosquito com modificações nos tanques de estoque de água com uma série de medidas legislativas, educação ambiental, controle químico e biológico (Gusman e Kouri, 2002; Gluber, 2004).

\section{CONCLUSÕES}

Entre os isolados com Bacillus thuringiensis obtidos o A-392 foi mais tóxico para larvas de $2^{\circ}$ instar de $A$. aegypti com mortalidade superior a 90\% das larvas de Aedes.

Entre os resultados obtidos verifica a necessidade de buscar novos isolados com toxicidade para larvas de $A$. aegypti, que possui potencialidade para produção de bioinseticidas eficiente contra esse inseto.

\section{RESUMO}

Este trabalho objetivou-se selecionar e identificar estirpes de Bacillus thuringiensis (Bt) obtidos de amostras de solo do estado de Tocantins que apresentaram toxicidade para o mosquito Aedes aegypti. Obteve-se isolados de $B t$ das amostras de solos obtidos e com maior número de colônias em solos com alto teor de argila e matéria orgânica. A atividade tóxica entre os isolados obtidos variou de 14,7 a $98 \%$ de mortalidade para larvas de $2^{\circ}$ estádio de $A$. aegypti, com destaque para o isolado A-392. Foram realizadas analise de SDSPAGE onde houve a presença de um peptídeos de aproximadamente $80 \mathrm{kDa}$, não sendo visualizado nos demais isolados, o a estirpe A-392 teve $98 \%$ de mortalidade das larvas de A. aegypti testadas, no 
período de 48 horas, utilizando uma concetração de 20 $\mu \mathrm{L} / \mathrm{mL}$ do caldo bacteriano. Verifica-se que $B$. Thuringiensis isoladas do estado do Tocantins apresenta resultados promissores para serem utilizadas na fabricação de um bioinseticidas contra as larvas deste mosquito.

Palavras-chave: Dengue, bio-inseticida, controle biologico

\section{REFERÊNCIAS}

Araujo, A. P.; Melo-Santos, M. A. V.; Carlos, S. O.; Rios, E. M. M.; Regis, L. (2007), Evolution of an experimental product based on Bacillus thuringiensis sorovar. Israelensis against Aedes aegypti larvae (Diptera: Culicidae). Biological Control, 41, 339-347.

Becker, N. (2002), Sterilization of Bacillus thuringiensis israelensis products by $\gamma$ radiation. Journal American Mosquito Control Association, 18, 57-62.

Brasil. Ministério da Saúde, (2009), Reunião de avaliação do monitoramento da resistência das populações de Aedes aegypti do Brasil. Ministério da Saúde, Brasília.

Carvalho, M. S. L.; Caldas, E. D.; Degallier, N.; Vilarinhos, P. T. R.; De Souza, L. C. K. R.; Yoshizawa, M. A. C.; Knox, M. B.; Oliveira, C. (2004), Suscetibilidade de larvas de Aedes aegypti ao inseticida temefós no Distrito Federal. Revista de Saúde Pública, 38, 623-629.

Couch, T. L. (2000), Industrial fermentation and formulation of entomopathogenic bacteria. In: Charles, J.-F., Delécluse, A., Nielsen-Leroux, C. (Eds.), Entomopathogenic bacteria: from laboratory to field application. Kluwer Academic Publishers, Dordrecht, 297-314p.

Chang, C.; Shen, W. K.; Wang, T. T.; Lin, Y. H.; Hsu, E. L.; Dai, S. M. (2009), A novel amino acid substitution in a voltage-gated sodium channel is associated with knockdown resistance to permethrin in Aedes aegypti. Insect Biochemistry and Molecular Biology, 39, 272-278.

Cox, J.; Grillet, M. E.; Ramos, O. M.; Amador, M.; Barrera, R. (2007), Habitat segregation of dengue vectors along an urban environmental gradient. American Journal of Tropical Medicine and Hygiene, 76, 820-826.
Espíndola, C. B.; Guedes, R. N.; De Souza, R. C. (2008), Avaliação da Eficácia do Bacillus thuringiensis var. israelensis no Controle de Formas imaturas do Aedes (Stegomyia) aegypti (Linnaeus, 1762) em Ambiente de Laboratório. EntomoBrasilis, 1, 10-13.

Goldberg, L. J. and Margalit, J. (1977), A bacterial spore demonstrating rapid larvicidial activity against Anopheles sergentii, Uranotaenia uguiculata, Culex univitattus, Aedes aegypti and Culex pipiens. Mosquito. News, 37, 355-361.

Glare, T. R. and O'Callaghan, M. (2000), Bacillus thuringiensis: biology, ecology and safety. Chichester: John Wiley, 350p.

Gluber, D. J. (2004), The changing epidemiology of yellow fever and dengue, 1900 to 2003: full circle. Comparative Immunology, Microbiology \& Infectious Diseases, 27, 319-330.

Guzman, M. G. and Kouri, G. (2002), Dengue: ans update. Journal of Infectious Diseases, 2, 33-42.

Habib, M. E. M.; Andrade, C. F. S. (1998), Bactérias entompatogênicas In: Alves, S.B. Controle microbiano de insetos. Piracicaba: FEALQ, 12, 383-446p.

Hofte, H. and Whiteley, H. R. (1989), Insecticidal crystal proteins of Bacillus thuringiensis. Microbiology Reviews, 53, 242-255.

Jung, Y. C.; Kim, S. U.; Côte, J. C.; Lecadet, M. M.; Chung, Y. S.; Bok, S. H. (1998), Characterization of a new Bacillus thuringiensis subsp. Higo strain isolated from rice bran in korea. Journal of invertebrate pathology, 71, 95-96.

Kroeger, A.; Horstick, O.; Riedl, C.; Kaiser, A.; Becker, N. (1995), The potential for malaria control with the biological larvicide Bacillus thuringiensis israelensis (Bti) in Peru and Ecuador. Acta Tropical, 60, 47-57.

Lecadet, M. M.; Chaufaux, J.; Ribier, J. E.; Lereclus, D. (1991), Construction of novel Bacillus thuringiensis strains with different insecticidal activities by transduction ande transformation. Applied and Environmental Microbiology, 58, 840-849. 
Lima, J. B. P.; Cunha, M. P. Da; R. C.; Silva, Jr. Da; Galardo, A. K. R.; Soares, S. S. Da; Braga, I. A.; Ramos, R. P. \& Valle, D. (2003), Resistance of Aedes aegypti to organophosphates in several municipalities in the state of Rio de Janeiro and Espírito Santo, Brazil. American Journal of Tropical Medicine Hygiene, 68, 329-333.

Macoris, M. L. G.; Andrighetti, M. T. M.; Takaku, L.; Glasser, C. M.; Garbeloto, V. C.; Bracco, J. E. (2003), Resistance of Aedes aegypti from the State of São Paulo, Brazil, to Organophosphates Insecticides. Memórias do Instituto Oswaldo Cruz, 98, 703-708.

Monnerat, R. G.; Soares, C. M. S. ; Gomes, A. C. M.; Jones, G.; Martins, E.; Praça, L.; Berry, C. (2009), Translocation and insecticidal activity of Bacillus thuringiensis bacteria living inside of plants. Microbial Biotechnology, 2, 1560-1562.

Monnerat, R. G.; Silva, S. F.; Silva-Werneck, J. (2001), O catálogo do banco de germoplasma de bactéria entomopatogênica do gênero Bacillus. Brasília: Embrapa Recursos Genéticos e Biotecnologia, 65p.

Petry, F.; Lozovei, A. L.; Ferraz, M. E.; Santos Neto, L. G. (2004), Controle integrado de espécies de Simulium (Diptera, Simuliidae) por Bacillus thuringiensis e manejos mecânicos no riacho e nos vertedouros de tanques de piscicultura, Almirante Tamandaré, Paraná, Brasil. Revista Brasileira de Entomologia, 48, 127-132.

Poupardin, R.; Reynaud, S.; Strode, C.; Ranson, H.; Vontas, J.; David, J. P. (2008), Crossinduction of detoxification genes by environmental xenobiotics and insecticides in the mosquito Aedes aegypti: impact on larval tolerance to chemical insecticides. Insect Biochemistry and Molecular Biology, 38, 540-551.

Prabakaran, G.; Hoti, S. L.; Manonmani, A. M.; Balaraman, K. (2008), Coconut water as a cheap source for the production of endotoxin of Bacillus thuringiensis var. israelensis, a mosquito control agent. Acta Tropica, 105, 35-38.
Sosa-Gómez, D. R.; Tigano, M. S.; Alves, S. B. (1998), Caraterização de entomopatógenos In: Alves, S.B. Controle microbiano de insetos. São Paulo: FEALQ, 22, 731-764.

Schnepf, E.; Crickmore, N.; Van Rie, J.; Lereclus, D.; Baum, J.; Feitelson, J.; Zeigler, D. R.; Dean, D. H. (1998), Bacillus thuringiensis and its pesticide crystal proteins. Microbiology and Molecular Biology Reviews, 62, 775-806.

Tikar, S. N.; Kumar, A.; Prasad, G. B.; Prakash, S. (2009), Temephos-induced resistance in Aedes aegypti and its cross-resistance studies to certain insecticides from India. Parasitology. Reserch, 105, 57-63.

Uribe, D.; Marinez, W.; Cerón, J. (2003), Distribution and diversity of cry genes in native strains of Bacillus thuringiensis obtained from different ecosystems from Colombia. Journal of Invertebrate Pathology, 82, 119-127.

Vilarinhos, P. T. R.; Dias, J. M. C. S.; Andrade, C. F. S.; Araújo- Coutinho, C. J. P. C. (1998), Uso de bactérias para o controle de culicídeos e simulídeos. In: Alves, S.B. Controle microbiano de insetos. Piracicaba: Fundação de Estudos Agrários Luiz de Queiroz, 80-447p.

Vilarinhos, P. T. R. and Monnerat, R. G. (2004), Larvicidal persistance of Bacillus thuringiensis israelensis formulations to control Aedes aegypti larvae. Journal of Ayub Medical College, 20, 311314.

Yousten, A. A. (1984), Bacillus sphaericus: microbiological factors related to its potential as a mosquito larvicide. Advances in Biotechnology Processes, 3, 315-343.

WHO [World Health Organization]. (1999), Microbial pest control agent Bacillus thuringiensis. Enviromental Health Criteria. Geneva, Switzerland: World Health Organization, 217p. 